\title{
Concurrent validity of the Alcohol Purchase Task for measuring the reinforcing efficacy of alcohol: an updated systematic review and meta-analysis
}

\author{
Victor Martínez-Loredo 1,3 (D, Alba González-Roz ${ }^{2,3}$ (D), Roberto Secades-Villa ${ }^{3}$ (D), \\ José R. Fernández-Hermida ${ }^{3}$ (D) \& James MacKillop 4
}

Department of Psychology and Sociology, University of Zaragoza, Zaragoza, Spain,' Department of Psychology, University of the Balearic Islands, Research Institute on Health Sciences, Palma de Mallorca, Spain, ${ }^{2}$ Department of Psychology, University of Oviedo, Oviedo, Spain ${ }^{3}$ and Peter Boris Centre for Addictions Research, St Joseph's Healthcare Hamilton/McMaster University, Hamilton, ON, Canada ${ }^{4}$

\begin{abstract}
Background and aims An early meta-analysis testing the concurrent validity of the Alcohol Purchase Task (APT), a measure of alcohol's relative reinforcing value, reported mixed associations, but predated a large number of studies. This systematic review and meta-analysis sought to: (1) estimate the relationships between trait-based alcohol demand indices from the APT and multiple alcohol indicators, (2) test several moderators and (3) analyze small study effects. Methods A meta-analysis of 50 cross-sectional studies in four databases $(n=18466$, females $=43.32 \%)$. Sex, year of publication, number of APT prices and index transformations (logarithmic, square root or none) were considered as moderators. Small study effects were examined by using the Begg-Mazumdar, Egger's and Duval \& Tweedie's trim-and-fill tests. Alcohol indicators were quantity of alcohol use, number of heavy drinking episodes, alcohol-related problems and hazardous drinking. APT indices were intensity (i.e. consumption at zero cost), elasticity (i.e. sensitivity to increases in costs), $O_{\max }$ (i.e. maximum expenditure), $P_{\max }$ (i.e. price associated to $O_{\max }$ ) and breakpoint (i.e. price at which consumption ceases). Results All alcohol demand indices were significantly associated with all alcohol-related outcomes $(r=0.132-0.494)$, except $P_{\max }$, which was significantly associated with alcohol-related problems only $(r=0.064)$. The greatest associations were evinced between intensity in relation to alcohol use, hazardous drinking and heavy drinking and between $O_{\max }$ and alcohol use. All the tested moderators emerged as significant moderators. Evidence of small-study effects was limited. Conclusions The Alcohol Purchase Task appears to have concurrent validity in alcohol research. Intensity and $O_{\max }$ are the most relevant indices to account for alcohol involvement.
\end{abstract}

Keywords Alcohol, alcohol purchase task, behavioral economics, concurrent validity, hazardous drinking, meta-analysis.

Correspondence to: Alba González-Roz, Research Institute of Health Sciences (IUNICS), University of the Balearic Islands, Carretera de Valldemossa Km. 7.5. E-07122, Palma de Mallorca, Spain. E-mail: alba.gonzalez@uib.es

Submitted 20 May 2020; initial review completed 9 September 2020; final version accepted 9 December 2020

\section{INTRODUCTION}

Alcohol misuse is a major contributor to morbidity and mortality world-wide. Drinking accounts for one-third of deaths due to cardiovascular diseases, and diabetes and is a risk factor for different cancers [1]. The associated costs of alcohol use is estimated at $\$ 249$ billion in the United States [2] and at $1-3.5 \%$ gross domestic product (GDP) in several European Union countries [3]. The analysis of conditions under which individuals engage in excessive drinking at the expense of other potentially available reinforcers has been extensively examined using behavioral economics (BE), a hybrid field integrating behavioral psychology and micro-economics [4]. Specifically, BE defines alcohol use fundamentally as an operant behavior and, consequently, the study of the reinforcing efficacy of alcohol, in general and over other reinforcers, constitutes a priority area in the field [5].

The analysis of reinforcing efficacy of drugs has shifted from progressive-ratio schedules in self-administration studies to estimated consumption via hypothetical purchases $[6,7]$. This latter option allows to assess 
drug-reinforcing value under different constraints (e.g. typical drinking situation versus acute states; availability of a single drug versus two or more) while reducing resource demand, participant burden and ethical concerns. In the alcohol field, the Alcohol Purchase Task (APT) provides a behavioral economic proxy of alcohol use valuation [8]. In addition to its sound psychometric properties [9], hypothetical APTs provide data that converge with actual APTs $[10,11]$ while reducing burden and eliminating ethical concerns, especially when assessing individuals with alcohol-related problems.

More specifically, the APT offers five demand indices capturing different aspects of the alcohol-reinforcing efficacy: intensity of demand (i.e. consumption at zero cost), elasticity of demand (i.e. sensitivity to increases in costs), $O_{\max }$ (i.e. maximum expenditure), $P_{\max }$ (i.e. price associated to $O_{\max }$ ) and breakpoint (i.e. price that suppresses consumption). Collectively, these five indices provide a comprehensive perspective on alcohol valuation and offer clinical and experimental insights. For example, heavy-drinking smokers show increased alcohol $O_{\max }$ and breakpoint [12], and adulterated alcohol solutions administered under devaluation paradigms specifically reduce alcohol choice via intensity decreases [13].

Fostered by the widespread use of hypothetical purchase tasks, Roma et al. [14] published an informed guidance on their construction, showing that price density (i.e. number of prices utilized) affected the estimation of demand indices. In a recent meta-analysis, price density moderated the relationship between $P_{\max }$, breakpoint and measures of quantity-frequency of illicit drug use [15], suggesting that the APT concurrent validity might also be affected by structural characteristics. This is important, as the evolving literature has used a variety of APT versions with prices ranging from 13 to $51[16,17]$. However, their impact over the relationship between each APT index and alcohol-related variables has yet to be systematically examined.

More generally, APT research has revealed heterogeneous estimates of associations between demand indices and alcohol-related variables. In attempts to synthesize these findings, two studies have meta-analyzed studies published up to 2015 [18] and 2017 [19]. Results from the first study showed that intensity and, to a lesser extent, $O_{\max }$, exhibited meaningful effect sizes, but the other demand indices were not implicated, which raised doubts about the validity of the APT. More recently, Zvorsky et al. [19] also supported the contribution of intensity and $O_{\text {max }}$, but its general scope and the fact that all alcohol use indicators were collapsed, precluded from examining specific associations between the APT indices and different patterns of alcohol use. Also, the moderating effects of individual (e.g. sex) and APT-related characteristics (e.g. price density, APT's indices transformation) were not explored, leaving the above-mentioned concerns as open questions. A recent meta-analysis of illicit drug demand found that females exhibited stronger correlations between $P_{\max }$, breakpoint and quantity-frequency and severity of illicit drug use [15]. However, the moderating role of sex in the association between alcohol demand indices and alcohol use has not been meta-analytically appraised. Given the existing sex and gender differences in terms of alcohol use and alcohol-related problems [20,21] and the high variation in female percentages in the preceding APT meta-analyses $[18,19]$, the potential moderating role of sex warrants further examination.

The current systematic review and meta-analysis addresses a number of the preceding gaps on the APT literature and entails an extension of previous existing meta-analyses $[18,19]$. It is a comprehensive and updated meta-analytical examination of the concurrent validity of the APT. Specifically, it sought to (1) meta-analyze the findings on cross-sectional relationships between APT indices, patterns of alcohol use (i.e. quantity of alcohol use, number of heavy drinking episodes) and negative consequences (i.e. alcohol-related problems, hazardous drinking), (2) to test potential moderators of the observed associations (i.e. sex, year of publication and APT-related characteristics) and (3) to assess the presence of small study effects.

\section{METHOD}

Literature search procedure and data extraction

Prior to the onset of the meta-analysis, a comprehensive protocol detailing the methods and procedures adopted was registered in the International Prospective Register of Systematic Reviews (PROSPERO) system for systematic reviews (ID: CRD42019137512) and published independently [22]. Both the review and meta-analysis were conducted in accordance with the Preferred Reporting Items for Systematic Reviews (PRISMA) statement [23] (see Supporting information, Table S1). Potential eligible studies were identified via searches of PubMed, PsycINFO, Scopus and Web of Science databases. As the first APT paper was published in 2006 [8], literature searches were conducted from inception to October, 2020 using the Boolean search terms that follow: (alcohol) AND (behavioral economic*) OR (purchase task) OR (alcohol demand) OR (reinforcing efficacy) OR (reinforcing value). Peer-review studies were retained for the meta-analysis if they met the following criteria: (1) were human studies; (2) were experimental or clinical studies analyzing the relationship between at least one baseline individual-level APT index and alcohol-related variables (i.e. alcohol use, binge drinking, alcohol-related problems, hazardous drinking). Because in-vivo laboratory studies using state-based APTs are qualitatively different from trait-based assessments 
indices [10,11,24,25], experimental studies using state-based APT versions were excluded. Also, data on elasticity of demand were only included when calculated through the two most widely used formulae [26,27]. When the same sample was used in more than one study, the study providing more information and a higher number of participants was retained. The 'participants' and 'procedure' sections of studies potentially based on the same dataset were compared to ensure their independence. In case of questions, corresponding authors were contacted to clarify this point. Finally, studies using other demand measures different than an APT, not reporting data at individual level or not reporting baseline data on either APT or alcohol-related variables were excluded.

The literature search was conducted by two reviewers who coded the studies independently on the following variables: authors (names), tittle (name), year of publication (year), country (name), sample characteristics (sample size, mean age, proportion of study participants who were female), APT-related characteristics (number and range of prices, type of APT's indices transformation), alcohol variables (questionnaire, unit of measure) and outcome measures (Pearson's or Spearman's coefficient effect sizes). No disagreement occurred regarding potential eligible studies. A total of 20 authors leading 35 studies were also contacted to provide the necessary data to conduct the meta-analysis. Of these, 18 provided the necessary data to permit inclusion of 32 studies in the meta-analysis.

\section{Meta-analytical approach}

Pearson's and Spearman's effect size correlations were used as primary effect sizes on the association between APT indices (intensity, elasticity, $O_{\max }, P_{\max }$ and breakpoint) and alcohol-related variables. Given the marked heterogeneity in study designs (i.e. treatmentseeking or community samples) and methods (i.e. variability in alcohol measures and APT-related characteristics), a random-effects model was adopted. Spearman's correlations were converted into Pearson's using the formula: $r=2 * \sin \left(r_{\mathrm{s}} \pi / 6\right)$ [28]. Cochran's $Q, I^{2}$ and tau $(\tau)$ were computed to characterize heterogeneity; $I^{2} \leq 25 \%$ suggests low heterogeneity, $\sim 50 \%$ suggests moderate heterogeneity and $\geq 75 \%$ suggests high heterogeneity across studies [29]. Additionally, a 95\% prediction interval was calculated following the formula reported by IntHout et al. [30]. To complement these analyses, a leave-one-out 'jackknife' sensitivity analysis was carried out. It consists of evaluating effect sizes with each study excluded and identifies studies with large contributions on the overall effect sizes, which can distort the pooled effect [31]. Systematic differences in effect sizes based on the alcohol-related variables (alcohol use, heavy drinking, alcohol-related problems and hazardous drinking) were also explored. Sex, year of publication and APT-related characteristics (i.e. number of APT prices and type of APT's indices transformation used) were also assessed as potential moderators on the obtained estimates using meta-regressions at a two-sided 95\% confidence level $(P<0.05)$. When performing meta-regressions on the effect of price density, one outlying value (i.e. 51 prices) in the study by Salzer et al. [16] was winsorized, as recommended by Tabachnick \& Fidell [32]. Based on the substantial heterogeneity of type of transformation used to correct for skewness and kurtosis across APT studies, a subgroup analysis of the observed associations by type of transformation (square root, log-based or none) was conducted as well. A thorough procedure was followed to assess for small-study effects using non-parametric and regression-based tests [33]: (1) the two-tailed Begg-Mazumdar test (i.e. rank correlation between the standard effect size and their variances, with deviations from zero indicating the presence of small study effects), and (2) the two-tailed Egger's test (i.e. asymmetry of the funnel plot with intercept values close to zero indicating lesser small study effects). Sensitivity analysis was subsequently performed following the Duval \& Tweedie's trim-and-fill approach (i.e. computation of the effect sizes after imputation of estimated missing studies) using the $\mathrm{L}_{0}$ estimator and exploring missing studies to the left of the mean, except for elasticity due to its inverse association. Despite sometimes leading to conservative results [34], this popular approach improves pooled estimates [35] and is considered as adequate [36]. No risk of bias assessment was performed.

\section{RESULTS}

\section{Sample characteristics}

Figure 1 depicts the PRISMA flow-chart on the review process. A total of 20736 studies were initially identified. After removing duplicates, 17705 records were screened at title and abstract levels and were discarded if they were not relevant to the study question. The 109 potentially relevant studies were assessed for eligibility. A total of 50 papers containing 52 studies were finally retained after applying the exclusion criteria.

Study characteristics are shown in Table 1. The median sample size was 191 (total sample size = 18466; range $=36-4790)$ and participants' mean age was 25.14 [standard deviation $(\mathrm{SD})=4.77$ ] years. Females comprised 0-90.6\% of the sample, with a weighted percentage of $43.32 \%$. APT structural characteristics varied substantially in terms of number of prices (range $=9-51$ ) and maximum price (range $=\$ 9-1120$ ). This latter range is significantly reduced if the two studies $[37,58]$ with extreme maximum prices (i.e. $\$ 100$ and $\$ 1120$, respectively) are removed $($ range $=\$ 9-40)$. Raw intensity $(58.00 \%, n=29), O_{\max }$ (54.35\%, $n=25), P_{\max }(62.16 \%, n=23)$, breakpoint 

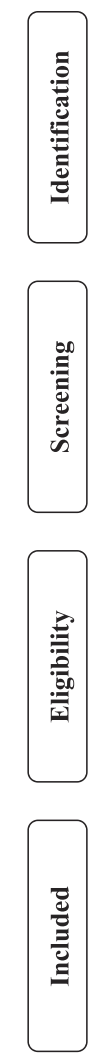

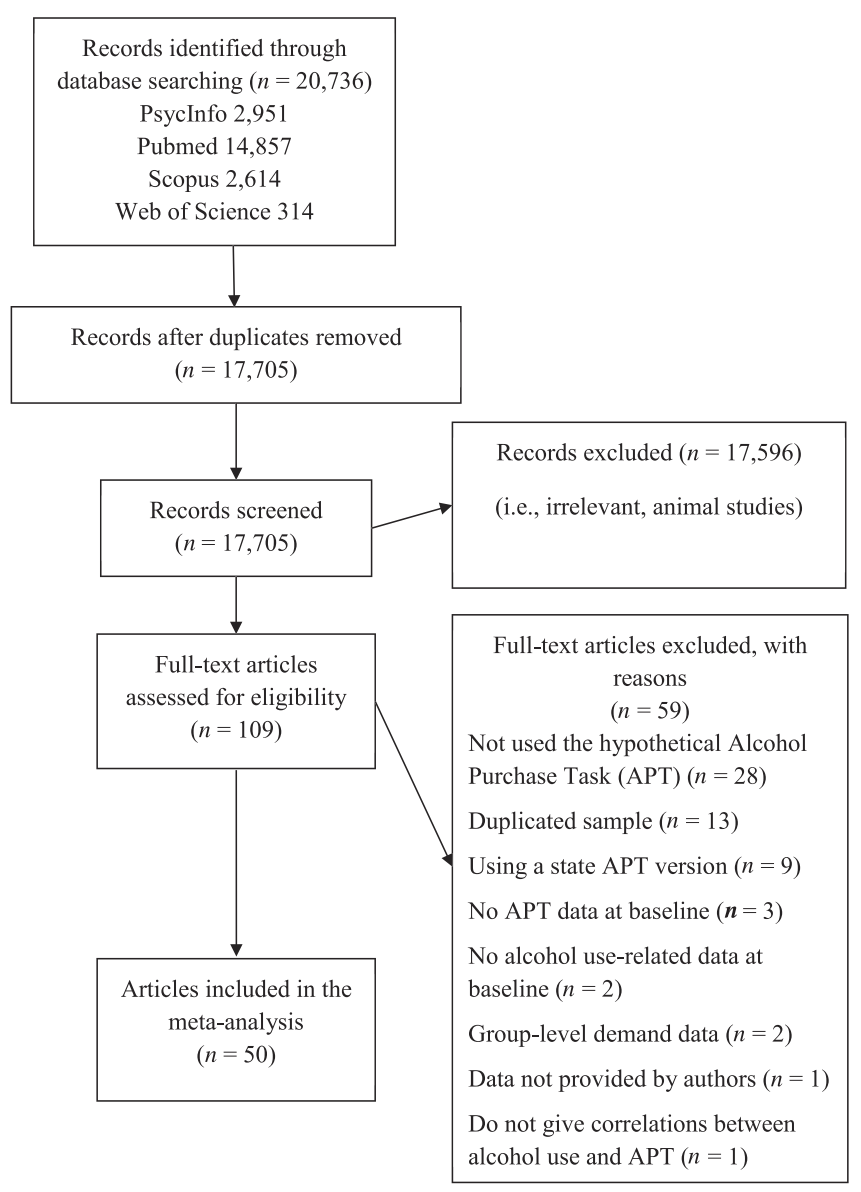

Figure I Preferred Reporting Items for Systematic Reviews and Meta-Analyses (PRISMA) flow-chart on the literature search procedure

$(74.42 \%, n=32)$ and elasticity $(56.82 \%, n=25)$ were used in most bivariate associations, followed by the logarithmic (\%: 24.00, 15.22, 18.92, 6.98, 22.73; $n: 12,7,7,3,10$, respectively) and square root $(\%: 18.00,30.43,18.92$, $18.60,20.45 ; n: 9,14,7,8,9$, respectively) transformations. Of note, $88.46 \%$ of studies $(n=46 / 52)$ were conducted in the United States.

\section{Average effect sizes and heterogeneity analyses}

Table 2 shows results on primary meta-analytical analyses and its associated heterogeneity calculations. Forest plots are presented in Data S1. All demand indices were significantly associated with all alcohol-related outcomes except for $P_{\max }$, which was significantly associated with alcohol-related problems only $(r=0.064, P=0.004)$. Significant effect sizes showed a wide range $(r=0.064-0.494)$, with intensity exhibiting moderateto-large effect sizes $(r=0.334-0.494)$, elasticity low-to-moderate $(r=-0.197$ to -0.132$)$ and $O_{\max }$ moderate $(r=0.230-0.354)$. Effect sizes for breakpoint $(r=0.137-0.155)$ and $P_{\max }(r=0.007-0.064)$ were small in magnitude. An analysis by alcohol variable showed larger effects of intensity $\left(Q_{(3)}=34.79, P<0.001\right)$ on alcohol use compared to heavy drinking and alcoholrelated problems $(r=0.494$ versus 0.383 and 0.334 , respectively) and on hazardous drinking $(r=0.437)$ compared to alcohol-related problems $(r=0334)$. The magnitude of the $O_{\max }$-alcohol use association was greater $\left(Q_{(3)}=16.623, P=0.001\right)$ than those observed for hazardous drinking and alcohol-related problems $(r=0354$ versus 0.239 and 0.230 , respectively). Breakpoint $\left(Q_{(3)}=0.557, P=0.906\right)$, elasticity $\left(Q_{(3)}=2.282\right.$, $P=0.516)$ and $P_{\max }\left(Q_{(3)}=4.315, P=0.229\right)$ did not differ across the assessed alcohol-related variables.

Results based on $I^{2}$ suggested a moderate-to-high heterogeneity in most relationships (see Table 2). Standard deviations of effect sizes across studies as computed by the $\tau$ statistic suggested heterogeneity for intensity in alcohol use ( $\tau=0.115)$ and heavy drinking $(\tau=0.132)$, and for elasticity in alcohol use $(\tau=0.124)$, heavy drinking $(\tau=0.145)$ and alcohol-related problems for elasticity $(\tau=0.126)$. Variations in confidence intervals between the overall analyses and the jackknife approach were small, suggesting a minimal impact of individual studies on the overall effects. The only exception was the lower limit of the $P_{\max }$-heavy drinking and the elasticity-heavy drinking associations, which increased by 5.1 and $5.6 \%$, 


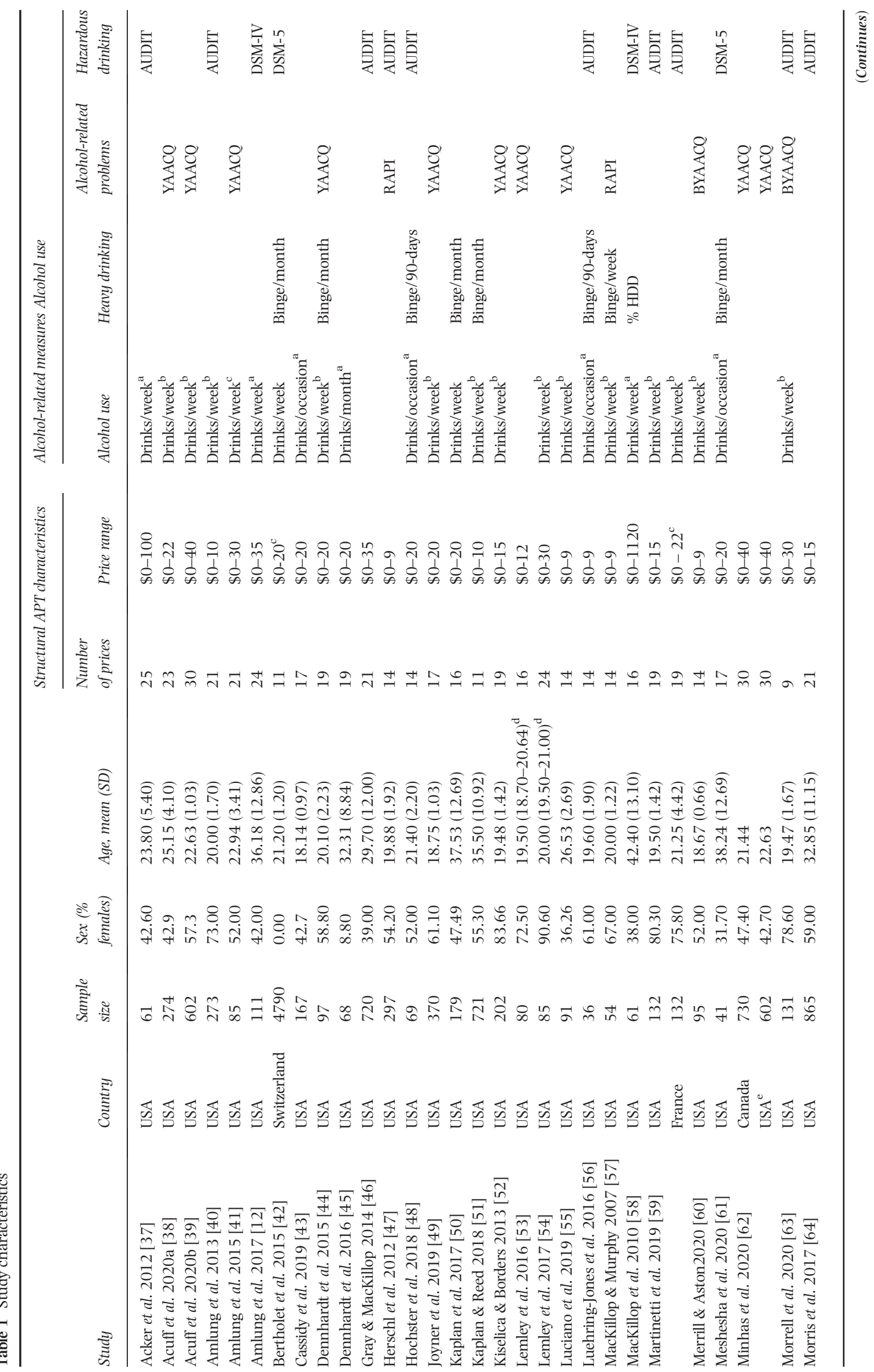




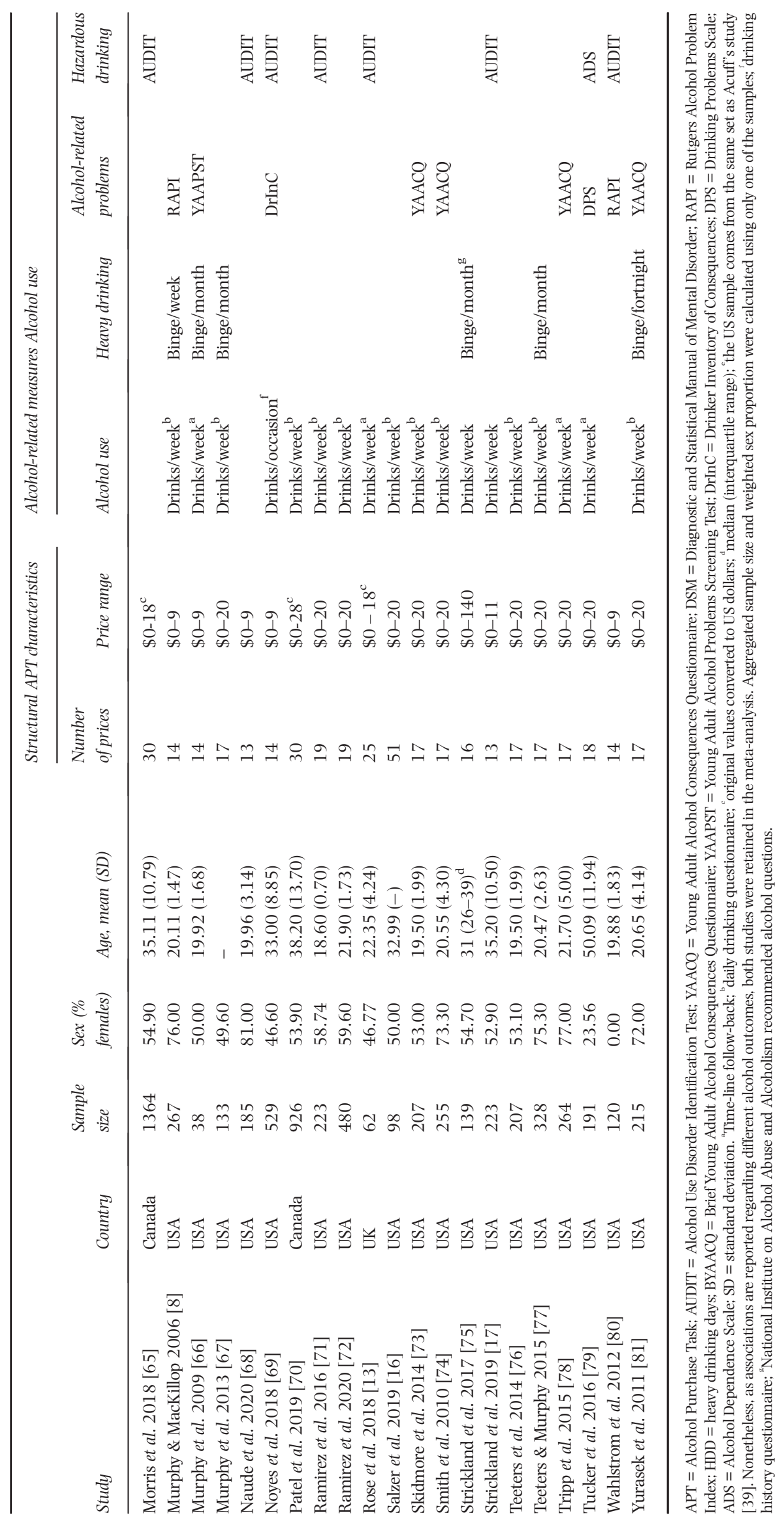




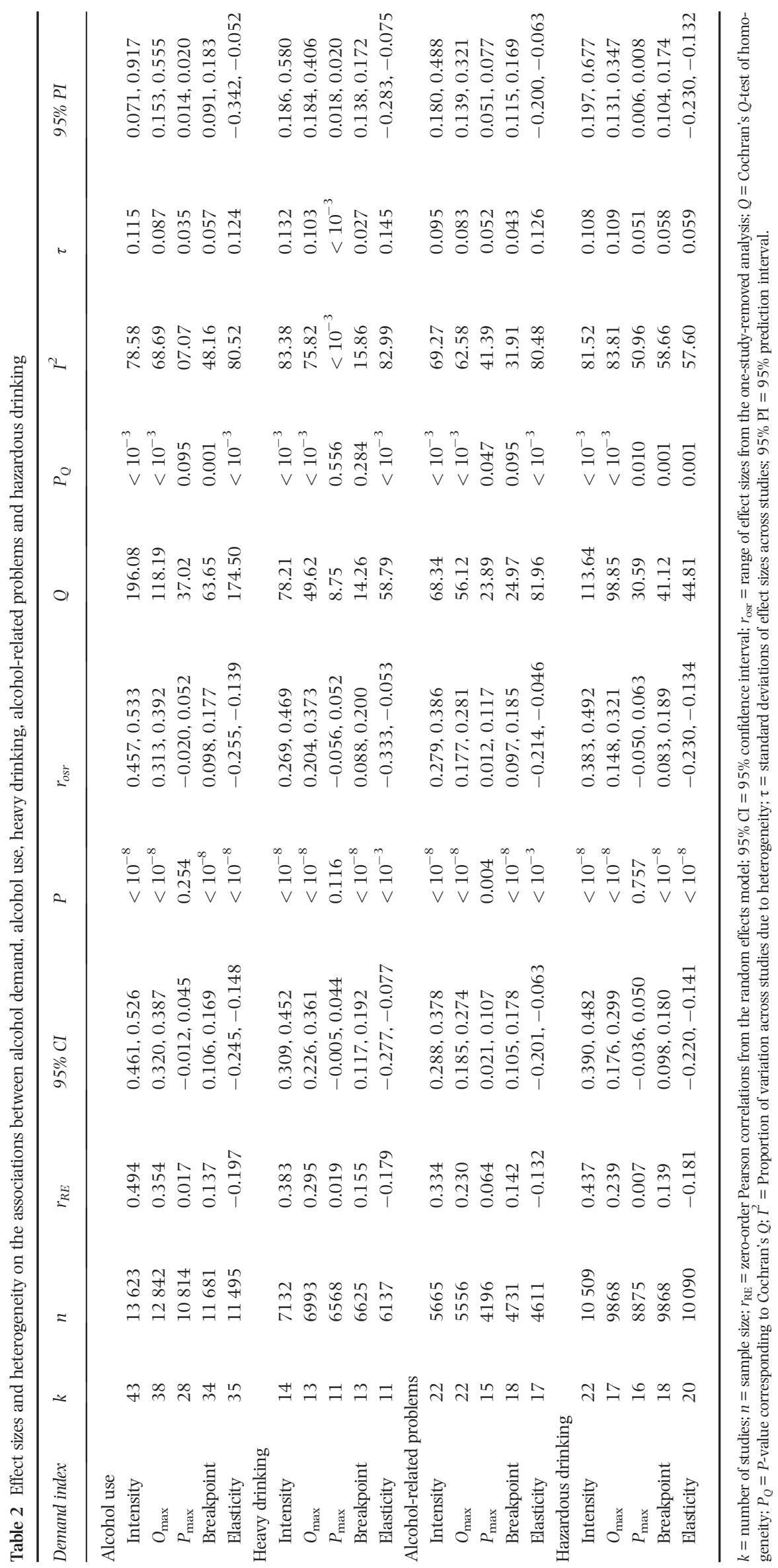


respectively, when the study by Bertholet et al. [42] was removed. This study also provided the lowest effect size limits in $50 \%(n=10 / 20)$ of the estimated effect sizes.

\section{Moderation analyses}

Regarding sex as a moderator, meta-regression analyses showed statistically significant effects of sex over intensity and elasticity effect sizes (see Table 3). Specifically, increased percentage of females strengthened the association between intensity and alcohol use $(P=0.025)$, alcohol-related problems $(P=0.001)$ and hazardous drinking $(P<0.001)$ and reduced the effect of elasticity on hazardous drinking $(P=0004)$. In terms of year of publication, more recent studies reported greater effect sizes between intensity and hazardous drinking $(P=0.048), P_{\max }$ and alcohol-related problems $(P=0.020)$ and smaller effect sizes between elasticity and hazardous drinking $(P=0.045)$.

With regard to APT assessment characteristics, meta-regressions showed non-significant effects of number of prices on any of the tested associations (Ps $=0.096-0.888)$. The type of index transformation significantly moderated the effect sizes for the heavy drinking variables. More precisely, square-root elasticity $\left(Q_{(2)}=22.41, P<0.001\right)$ yielded a larger effect size $(r=-0.729, n=1)$ than the $\log (r=-0.231, n=4)$ and untransformed ones $(r=-0.083, n=6)$.

\section{Small study effects}

According to the Begg-Mazumbar and the two-sided Egger's tests, there was no evidence of small study effects in $85 \%$ of the associations (see Table 4). The exceptions included Egger's test in the association between $O_{\max }$ and alcohol use; elasticity and hazardous drinking; and in the breakpoint-heavy drinking association. Despite these significant associations, they may be attributable to its high between-study heterogeneity, as suggested by the $Q, I^{2}$ and $\tau$-statistics (see Table 2).

Finally, the Duval \& Tweedie's trim-and-fill procedure suggested the influence of nine potential unpublished studies on the association between elasticity and alcohol use and one for the intensity-hazardous drinking association (see Table 4). The imputation of these potentially unreported studies decreased the estimated effect size for elasticity-alcohol use by $26.9 \%$ (from -0.197 to -0.144 ), and for intensity-hazardous drinking by $1.14 \%$ (from 0.437 to 0.432 ).

\section{DISCUSSION}

This systematic review and meta-analysis provides a comprehensive, updated account of the APT's concurrent validity in the burgeoning literature in this area, and addresses how a number of other variables affect its links with diverse aspects of alcohol involvement. All the demand indices except $P_{\max }$ were significantly associated with all alcohol-related outcomes, although with substantial differences in effect sizes. The greatest associations were evinced between intensity and all alcohol outcomes and between $O_{\text {max }}$ and alcohol use. Results also suggested significant effects of sex, year of publication and type of APT's indices transformation on meta-analytical findings. Lastly, some evidence of small study effects was obtained, especially for elasticity and alcohol use. Nonetheless, meta-analytical estimates based on imputed effects did not substantially alter the significance or magnitude of effects.

Moderate-to-large effect sizes were observed for intensity, moderate for $O_{\max }$ and small for elasticity and breakpoint. Similar results have been noted in meta-analyses of cross-sectional relationships with the demand for cigarettes [82] and illicit drugs [15], which indicates that these associations generalize across substances. The reported variations in effect sizes across APT indices converges with the multi-dimensional nature of drug-reinforcing efficacy [7] and they highlight the relevance of demand volumetric characteristics (intensity and $O_{\max }$ ) in relation to alcohol misuse [83], often comprising the 'amplitude' latent component of demand [83,84]. Notably, in-treatment reductions of these indices predict alcohol use outcomes after a brief intervention [85], and they are the most sensitive indices to experimental manipulation of individuals' contexts through cue exposure, increased stress/negative affect, opportunity cost or behavioral interventions [86]. More generally, findings support the validity of briefer assessments of alcohol demand to zero in on intensity and $O_{\max }$. While intensity captures the unconstrained reinforcing value of alcohol (i.e. consumption at no cost), $O_{\max }$ has been suggested to capture the most relevant features of motivation in the context of constraint [83], represented by the maximum effort (i.e. expenditure) deployed to obtain the drug. As such, these indices may inform about the magnitude of constraints or alternative reinforcers that should be implemented in preventive (e.g. availability and accessibility) and treatment (e.g. contingency management) interventions to compete against alcohol use.

Variations in effect sizes were partially explained by several variables. Sex worked as moderator on several of the observed effects for elasticity and intensity. Studies with a greater proportion of females strengthened the associations between intensity and alcohol use, related-problems and hazardous drinking. However, the elasticity and hazardous drinking association was weakened by female sex. Contrary to recent findings in illicit drugs [15], these results suggest the relevance of the volumetric demand 


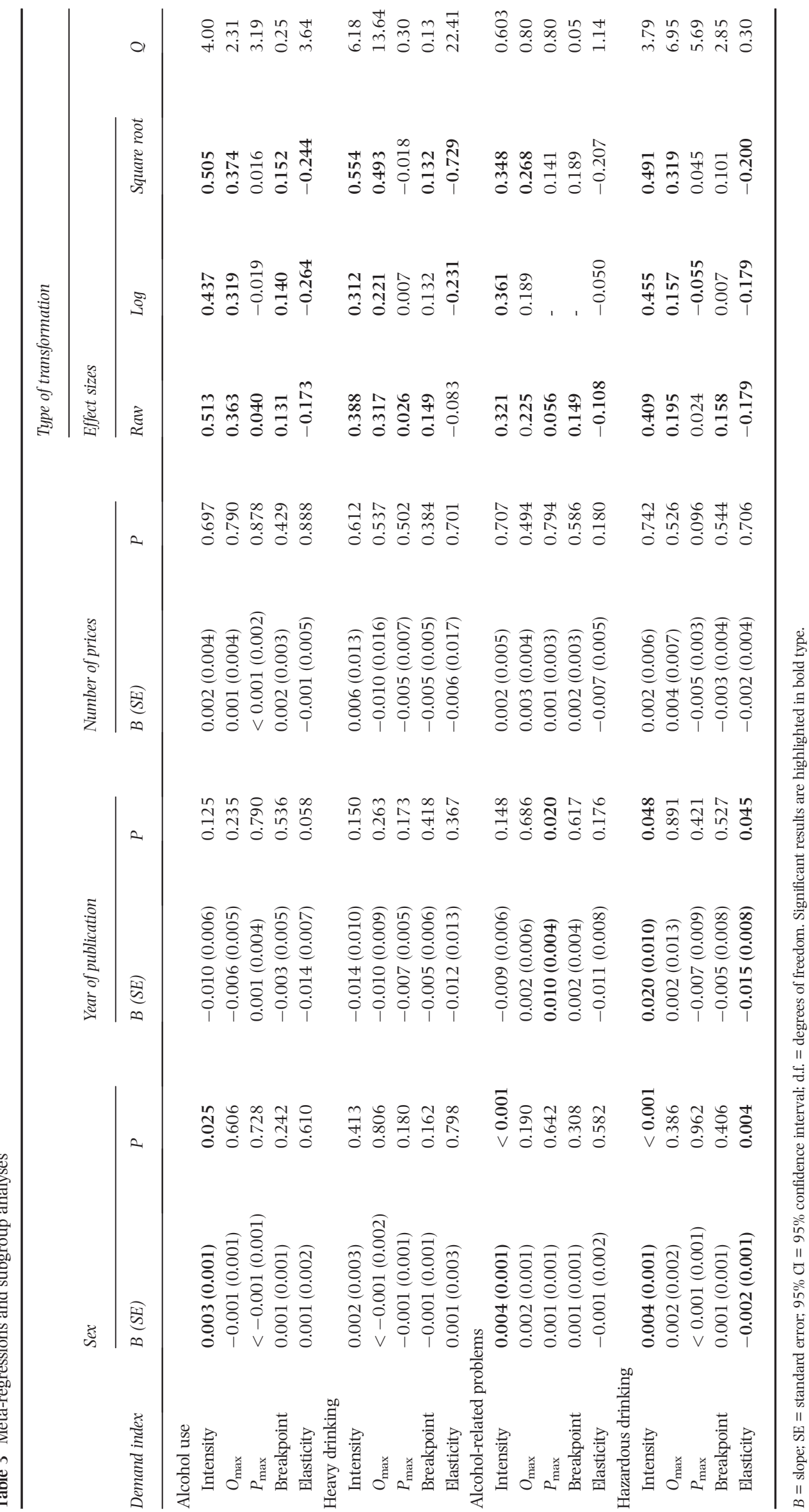


Table 4 Small study effects assessment

\begin{tabular}{|c|c|c|c|c|c|c|}
\hline \multirow[b]{2}{*}{ Demand index } & \multicolumn{2}{|c|}{ Begg-Mazumdar test } & \multicolumn{2}{|l|}{ Egger's regression analysis } & \multicolumn{2}{|c|}{ Duval \& Tweedie's trim-and-fill procedure } \\
\hline & $\tau$ & $P$ & Intercept (95\% IC) & $P$ & $n_{\text {trimmed }}$ & Difference \\
\hline \multicolumn{7}{|l|}{ Alcohol use } \\
\hline Intensity & -0.207 & 0.05 & $0.151(-1.03,1.33)$ & 0.796 & 0 & 0 \\
\hline$O_{\max }$ & -0.129 & 0.253 & $-1.187(-2.12,-0.25)$ & 0.014 & 0 & 0 \\
\hline$P_{\max }$ & -0.188 & 0.161 & $-0.658(-1.29,0.12)$ & 0.101 & 0 & 0 \\
\hline Breakpoint & -0.184 & 0.127 & $-0.592(-1.38,0.20)$ & 0.137 & 0 & 0 \\
\hline Elasticity & 0.111 & 0.349 & $-1.144(-2.38,0.97)$ & 0.07 & 9 & -0.053 \\
\hline \multicolumn{7}{|l|}{ Heavy drinking } \\
\hline Intensity & -0.264 & 0.189 & $-0.826(-2.89,1.24)$ & 0.401 & 0 & 0 \\
\hline$O_{\max }$ & -0.167 & 0.428 & $-1.415(-3.01,0.18)$ & 0.076 & 0 & 0 \\
\hline$P_{\max }$ & 0.109 & 0.64 & $-0.231(-1.15,0.69)$ & 0.583 & 0 & 0 \\
\hline Breakpoint & -0.346 & 0.100 & $-1.09(-1.75,-0.43)$ & 0.004 & 0 & 0 \\
\hline Elasticity & -0.145 & 0.533 & $-0.73(-3.05,1.58)$ & 0.492 & 0 & 0 \\
\hline \multicolumn{7}{|c|}{ Alcohol-related problems } \\
\hline Intensity & 0.048 & 0.756 & $0.601(-1.69,2.89)$ & 0.590 & 0 & 0 \\
\hline$O_{\max }$ & 0.117 & 0.446 & $-0.007(-2.03,2.02)$ & 0.990 & 0 & 0 \\
\hline$P_{\max }$ & 0.0 & 0.999 & $0.229(-1.71,2.17)$ & 0.802 & 0 & 0 \\
\hline Breakpoint & -0.255 & 0.14 & $0.143(-1.45,1.73)$ & 0.851 & 0 & 0 \\
\hline Elasticity & -0.037 & 0.837 & $-0.937(-2.24,4.11)$ & 0.539 & 0 & 0 \\
\hline \multicolumn{7}{|c|}{ Hazardous drinking } \\
\hline Intensity & -0.165 & 0.284 & $1.294(-0.26,2.85)$ & 0.098 & 1 & 0.005 \\
\hline$O_{\max }$ & -0.154 & 0.387 & $-0.598(-2.61,1.42)$ & 0.537 & 0 & 0 \\
\hline$P_{\max }$ & -0.142 & 0.444 & $-0.221(-1.39,0.94)$ & 0.69 & 0 & 0 \\
\hline Breakpoint & -0.17 & 0.325 & $-0.353(-1.57,0.87)$ & 0.549 & 0 & 0 \\
\hline Elasticity & 0.068 & 0.673 & $-1.151(-2.15,-0.15)$ & 0.026 & 0 & 0 \\
\hline
\end{tabular}

$\tau=$ Kendall's tau; $95 \%$ CI $=95 \%$ confidence interval. Significant results are highlighted in bold type.

characteristics regarding explaining alcohol involvement in females, which may be driven by biological factors related to higher sensitivity to alcohol [20]. Even though females may consume less alcohol than males, they are more vulnerable to alcohol effects and have exacerbated medical and interpersonal difficulties [87,88], which may account for higher magnitude effects for intensity on alcohol use, related problems and hazardous drinking. Finally, as alcohol use in men is considered more normative and is generally higher epidemiologically, it may be that demand in females taps intrinsic alcohol-reinforcing values more incisively. In other words, higher demand in females may be more specific to alcohol reinforcing properties itself, and thus be more clinically significant than higher demand in males. On another note, the reduced association between pricing-related indices (i.e. elasticity) and hazardous drinking observed in samples with a greater percentage of females suggests a relatively lower impact of price-based policies on females' demand compared to men. That is, as females reach higher blood alcohol concentrations (BACs) than males (i.e. present more sensitivity to alcohol), even at same alcohol doses, they may assume higher unit costs [89], especially in the context of drinking to cope [90].

The contribution of drinking motives may play a role on accounting for such effects, commensurate with studies reporting its mediating effect on the relationship between alcohol demand, alcohol use and related problems in college and adult samples [45]. Drinking motives, particularly social and drinking to cope, have been linked to female sex in pre-clinical [91] and human research [92], and has been suggested to modulate the effect of alcohol-reinforcing efficacy and alcohol use and problems $[45,81,90]$. These drinking motives could lead to social/interpersonal, job and financial strains which map onto several of the items contained on the scales used to measure alcohol use consequences.

Year of publication also moderated several of the observed associations. We found a strengthened effect for the intensity-hazardous drinking association in more recent studies. The fact that the Alcohol Use Disorders Identification Test (AUDIT) is being increasingly used to assess this pattern of alcohol use symptoms may partially account for this finding. More precisely, more than 83.3\% (10 of 12) of the studies published from 2017 to 2020 used the AUDIT compared to $70 \%$ (seven of 10) of studies published from 2006 to 2016. Given that the AUDIT includes frequency and quantity items and because they are highly correlated to intensity, this finding might be arguably attributed to this methodological element, rather than changes in sample characteristics or other variables. This 
may also account for the apparent contradiction of the diminishing association across years between elasticity and hazardous drinking. Despite that more recent studies used more balanced samples in terms of sex, and a lower percentage of females is associated with an increasing association between elasticity and hazardous drinking, the growing use of the AUDIT for assessing hazardous drinking may lead to a lower relevant role of elasticity on deleterious alcohol use patterns compared to other measures (e.g. DSM criteria). However, this remains speculative, as this hypothesis could not be tested directly.

The use of different mathematical transformations of APT's indices has yielded significant variation in the studied associations. In more recent studies there was an increasing use of logarithmic over square-root transformations, which consistently produced lower effects in moderation analyses, and may also help to explain the reduced correlations between elasticity and hazardous drinking across years. What is somewhat concerning is that virtually no study provided a detailed justification for using one or other transformation or reported changes in measures of dispersion. Importantly, transforming data in most circumstances does not reduce variability [93] and non-transformed indices in some ways may be more desirable on a theoretical and practical level, but obviously have trade-offs in terms of meeting typical statistical assumptions. Reporting both transformed and non-transformed data in the Supporting information might help to generalize findings beyond individual studies. Back-transformation is a commonly accepted practice [94,95], although it is only recommended for means and confidence intervals.

Some limitations inherent to the reviewed studies should be considered. The percentage of females was calculated based on socio-demographic characteristics and not on participants with valid APT data. Nonetheless, excluded participants are usually minimal, and consequently using this percentage may cause minimal deviation. This meta-analysis did not address the potential influence of psychiatric comorbidities in the reported effect sizes, as most studies were based on the general population; nor did it address other APT structural characteristics, such as the vignette instructions, which warrants further consideration. Also, the small number of works reporting each alcohol-related indicator reduces power in moderation analyses, and no risk of bias assessment was performed. The cross-sectional nature of this study reflects the state of the literature, but limits the extent to which the role of demand in the etiology or progression of alcohol misuse can be addressed. Finally, as conclusions are drawn based on aggregated samples, this meta-analysis cannot rule out potential ecological bias (i.e. systematic differences between individual- and group-level effects). The study also has several strengths that are worthy of mention. Besides using a pre-registered, peer-reviewed and published protocol and following a comprehensive search strategy, the present meta-analysis examined the effect sizes of APT indices regarding multiple alcohol-related variables and covered different patterns of alcohol use involvement. Also, it included several potentially relevant moderators of such effects and assessed small study effects using multiple metrics.

In summary, the present results provide a comprehensive up-to-date review of the concurrent validity of alcohol demand as measured by the APT in relation to alcohol misuse. Intensity and $O_{\max }$ are the most relevant to account for alcohol use involvement, and exhibit the highest promise to ultimately be used as diagnostic or prognostic tools. There has been a recent increasing interest to use demand levels as clinical tools that would trigger the use of different treatment intensities or modalities. In this sense, APT measures would be of help to identify subgroups of individuals for whom specific interventions are particularly effective. The fact that the association between APT and alcohol involvement was moderated by sex suggests different maintaining or etiological variables for alcohol use. For example, as problems in emotional regulation are more relevant in females, and given that intense negative affect is believed to enhance the reinforcing efficacy of alcohol [52], the former may be an important gender-related risk factor leading to more problematic use and poor treatment response. Finally, it is worth noting that although the current systematic review and meta-analysis is supportive of the concurrent validity of alcohol demand as measured by the APT, it cannot speak to the etiological or maintaining role of alcohol demand. This meta-analysis suggests robust correlations (particularly for intensity and $O_{\max }$ ) but cannot speak to causation. Longitudinal studies on demand remain scarce, making them a high priority for the future.

\section{Declaration of interests}

J.M. is a principal in a private company, BEAM Diagnostics, Inc., but no commercial products fall within the scope of the review. No other authors have any declarations to disclose.

\section{Acknowledgements}

This research was supported by two grants from the National Agency of Research of the Spanish Ministry of Science, Innovation and Universities and the European Regional Development Fund MINECO/FEDER (BES-2015073327 and BES-2016-076663), by grants from the Canadian Institutes of Health Research and National Institutes of Health (AA025911 and AA024930) and by the Peter Boris Chair in Addictions Research (JM). 


\section{Author contributions}

Victor Martinez-Loredo: Conceptualization; data curation; formal analysis; investigation; methodology; software; writing-original draft. Alba González-Roz: Conceptualization; data curation; formal analysis; investigation; methodology; software; supervision; writing-original draft; writing-review \& editing. Roberto Secades-Villa: Writing-original draft; writing-review \& editing. José Fernández-Hermida: Writing-original draft; writing-review \& editing. James MacKillop: Funding acquisition; methodology; supervision.

\section{References}

1. World Health Organization (WHO). Global Status Report on Alcohol and Health. Luxembourg: WHO; 2014. Available at: https://www.who.int/substance_abuse/publications/ alcohol_2014/en/ (accessed 20 October 2020).

2. Sacks J. J., Gonzales K. R., Bouchery E. E., Tomedi L. E., Brewer R. D. 2010 national and state costs of excessive alcohol consumption. Am J Prev Med 2015; 49: e73-e79. Available at: $\quad$ http://www.ncbi.nlm.nih.gov/pubmed/26477807 (accessed 20 October 2020).

3. Barrio P., Reynolds J., Garcia-Altes A., Gual A., Anderson P. Social costs of illegal drugs, alcohol and tobacco in the European Union: a systematic review. Drug Alcohol Rev 2017; 36: 578-88. Available at: http://www.ncbi.nlm.nih. gov/pubmed/28334460 (accessed 20 October 2020).

4. MacKillop J. The behavioral economics and neuroeconomics of alcohol use disorders. Alcohol Clin Exp Res 2016; 40: 672-85. Available at: http://www.ncbi.nlm.nih.gov/ pubmed/26993151 (accessed 20 October 2020).

5. Acuff S. F., Dennhardt A. A., Correia C. J., Murphy J. G. Measurement of substance-free reinforcement in addiction: a systematic review. Clin Psychol Rev 2019; 70: 79-90. Available at: http://www.ncbi.nlm.nih.gov/pubmed/30991244 (accessed 20 October 2020).

6. Petry N. M., Bickel W. K. Polydrug abuse in heroin addicts: a behavioral economic analysis. Addiction 1998; 93: 321-35. Available at: https://pubmed.ncbi.nlm.nih.gov/10328041/ (accessed 20 October 2020).

7. Bickel W. K., Marsch L. A., Carroll M. E. Deconstructing relative reinforcing efficacy and situating the measures of pharmacological reinforcement with behavioral economics: a theoretical proposal. Psychopharmacology 2000; 153: 44-56. Available at: http://www.ncbi.nlm.nih.gov/pubmed/ 11255928 (accessed 20 October 2020).

8. Murphy J. G., MacKillop J. Relative reinforcing efficacy of alcohol among college student drinkers. Exp Clin Psychopharmacol 2006; 14: 219-27. Available at: http://www.ncbi.nlm.nih. gov/pubmed/16756426 (accessed 20 October 2020).

9. Kaplan B. A., Foster R. N. S., Reed D. D., Amlung M., Murphy J. G., MacKillop J. Understanding alcohol motivation using the alcohol purchase task: a methodological systematic review. Drug Alcohol Depend 2018; 191: 117-40. Available at: http://www.ncbi.nlm.nih.gov/pubmed/30099174 (accessed 20 October 2020).

10. Amlung M., MacKillop J. Further evidence of close correspondence for alcohol demand decision making for hypothetical and incentivized rewards. Behav Processes 2015; 113:
187-91. Available at: https://www.ncbi.nlm.nih.gov/ pubmed/25712039 (accessed 20 October 2020).

11. Amlung M., Acker J., Stojek M., Murphy J. G. MacKillop J. is talk 'cheap'? An initial investigation of the equivalence of alcohol purchase task performance for hypothetical and actual rewards. Alcohol Clin Exp Res 2012; 36: 716-24. Available at: https://www.ncbi.nlm.nih.gov/pubmed/22017303 (accessed 20 October 2020).

12. Amlung M., MacKillop J., Monti P. M., Miranda R. Jr. Elevated behavioral economic demand for alcohol in a community sample of heavy drinking smokers. I Stud Alcohol Drugs 2017; 78: 623-8. Available at: https://www.ncbi.nlm.nih. gov/pubmed/28728645 (accessed 20 October 2020).

13. Rose A. K., Brown K., MacKillop J., Field M., Hogarth L. Alcohol devaluation has dissociable effects on distinct components of alcohol behaviour. Psychopharmacology 2018; 235: 1233-44. Available at: http://www.ncbi.nlm. nih.gov/pubmed/29480437 (accessed 20 October 2020).

14. Roma P. G., Hursh S. R., Hudja S. Hypothetical purchase task questionnaires for behavioral economic assessments of value and motivation. Manag Decis Econ 2016; 37: 306-23.

15. Strickland J. C., Campbell E. M., Lile J. A., Stoops W. W. Utilizing the commodity purchase task to evaluate behavioral economic demand for illicit substances: a review and metaanalysis. Addiction 2019; 115: 393-406. Available at: http://www.ncbi.nlm.nih.gov/pubmed/31454109 (accessed 20 October 2020).

16. Salzer A. R., Gelino B. W., Reed D. D. Left-digit pricing effects in a high-resolution examination of hypothetical operant demand for alcohol. Behav Processes 2019; 165: 51-7. Available at: http://www.ncbi.nlm.nih.gov/pubmed/31121215 (accessed 20 October 2020).

17. Strickland J. C., Alcorn J. L., Stoops W. W. Using behavioral economic variables to predict future alcohol use in a crowdsourced sample. J Psychopharmacol 2019; 33: 779-90. Available at: http://www.ncbi.nlm.nih.gov/ pubmed/30789298 (accessed 20 October 2020).

18. Kiselica A. M., Webber T. A., Bornovalova M. A. Validity of the alcohol purchase task: a meta-analysis. Addiction 2016; 111: 806-16. Available at: http://www.ncbi.nlm.nih.gov/ pubmed/26616514 (accessed 20 October 2020).

19. Zvorsky I., Nighbor T. D., Kurti A. N., DeSarno M., Naudé G., Reed D. D., et al. Sensitivity of hypothetical purchase task indices when studying substance use: a systematic literature review. Prev Med 2019; 128: 105789. Available at: https:// pubmed.ncbi.nlm.nih.gov/31400376/ (accessed 20 October 2020).

20. Erol A., Karpyak V. M. Sex and gender-related differences in alcohol use and its consequences: contemporary knowledge and future research considerations. Drug Alcohol Depend 2015; 156: 1-13. Available at: http://www.ncbi.nlm.nih. gov/pubmed/26371405 (accessed 20 October 2020).

21. Salvatore J. E., Cho S. B., Genes D. D. M. Environments, and sex differences in alcohol research. I Stud Alcohol Drugs 2017; 78: 494-501. Available at: http://www.ncbi.nlm.nih. gov/pubmed/28728631 (accessed 20 October 2020).

22. González-Roz A., Martinez-Loredo V., Secades-Villa R., Amlung M., McKillop J. Concurrent validity of the alcohol purchase task in relation to alcohol involvement: protocol for a systematic review and meta-analysis. BMJ Open 2020; 10: e035400. Available at: https://pubmed.ncbi.nlm.nih. gov/32595153 (accessed 20 October 2020).

23. Moher D., Liberati A., Tetzlaff J., Altman D. G., The PRISMA Group Preferred reporting items for systematic reviews and 
meta-analyses: the PRISMA statement. PLOS Med 2009; 6: e1000097. Available at: https://pubmed.ncbi.nlm.nih.gov/ 19621072/ (accessed 20 October 2020).

24. Amlung M., MacKillop J. Understanding the effects of stress and alcohol cues on motivation for alcohol via behavioral economics. Alcohol Clin Exp Res 2014; 38: 1780-9. Available at: http://www.ncbi.nlm.nih.gov/pubmed/24890323 (accessed 20 October 2020).

25. Owens M. M., Ray L. A., MacKillop J. Behavioral economic analysis of stress effects on acute motivation for alcohol. J Exp Anal Behav 2015; 103: 77-86. Available at: http:// www.ncbi.nlm.nih.gov/pubmed/25413719 (accessed 20 October 2020)

26. Hursh S. R., Silberberg A. Economic demand and essential value. Psychol Rev 2008; 115: 186-98. Available at: http:// www.ncbi.nlm.nih.gov/pubmed/18211190 (accessed 20 October 2020)

27. Koffarnus M. N., Franck C. T., Stein J. S., Bickel W. K. A modified exponential behavioral economic demand model to better describe consumption data. Exp Clin Psychopharmacol 2015; 23: 504-12. Available at: http://www.ncbi.nlm.nih. gov/pubmed/26280591 (accessed 20 October 2020).

28. Pearson K. Mathematical contributions to the theory of evolution. XVI. On further methods of determining correlation. In: Pearson K., Nettleship E., editors. Drapers' Company Research Memoirs. Cambridge, UK: Cambridge University Press; 1907, p. 39

29. Higgins J. P., Thompson S. G., Deeks J. J., Altman D. G. Measuring inconsistency in meta-analyses. BMJ 2003; 327: 557-60. Available at: http://www.ncbi.nlm.nih.gov/pubmed/ 12958120 (accessed 20 October 2020).

30. IntHout J., Ioannidis J. P., Rovers M. M., Goeman J. J. Plea for routinely presenting prediction intervals in meta-analysis. BMJ Open 2016; 6: e010247. Available at: http://www. ncbi.nlm.nih.gov/pubmed/27406637 (accessed 20 October 2020).

31. Greenhouse J. B., Iyengar S. Sensitivity analysis and diagnostics. In: Cooper H., Hedges L. V., Valentine J. C., editors. The Handbook of Research Synthesis and Meta-Analysis. New York, NY: Russel Sage Foundation; 1994, pp. 393-7.

32. Tabachnick B. G., Fidell L. S. Using Multivariate Statistics, 5th edn. New York, NY: Allyn and Bacon; 2007.

33. Schwarzer G., Carpenter J. R., Rücker R. Small-study effects in meta-analysis. In: Schwarzer G., Carpenter J. R., Rücker R., editors. Meta-analysis with $R$ (use R!). Cham, Switzerland: Springer International Publishing; 2015.

34. Schwarzer G., Carpenter J. R., Rücker R. Empirical evaluation suggests Copas selection model preferable to trim-and-fill method for selection bias in meta-analysis. J Clin Epidemiol 2010; 63: 282-8. Available at: https://pubmed.ncbi.nlm. nih.gov/19836925 (accessed 20 October 2020).

35. Peters J. L., Sutton A. J., Jones D. R., Abrams K. R., Rushton L. Performance of the trim and fill method in the presence of publication bias and between-study heterogeneity. Stat Med 2007; 26: 4544-62. Available at: https://pubmed.ncbi.nlm. nih.gov/17476644 (accessed 20 October 2020).

36. Shi J., Lin L. The trim-and-fill method for publication bias: practical guidelines and recommendations based on a large database of meta-analyses. Medicine 2019; 98: e15987. Available at: https://pubmed.ncbi.nlm.nih.gov/31169736 (accessed 20 October 2020).

37. Acker J., Amlung M., Stojek M., Murphy J. G., MacKillop J. Individual variation in behavioral economic indices of the relative value of alcohol: incremental validity in relation to impulsivity, craving, and intellectual functioning. $J$ Exp Psychopathol 2012; 3: 423-36.

38. Acuff S. F., Soltis K. E., Murphy J. G. Using demand curves to quantify the reinforcing value of social and solitary drinking. Alcohol Clin Exp Res 2020; 44: 1497-507. Available at: https://pubmed.ncbi.nlm.nih.gov/32472649 (accessed 20 October 2020).

39. Acuff S. F., MacKillop J., Murphy J. G. Integrating behavioral economic and social network influences in understanding alcohol misuse in a diverse sample of emerging adults. Alcohol Clin Exp Res 2020; 44: 1444-155. Available at: https:// pubmed.ncbi.nlm.nih.gov/32472649 (accessed 20 October 2020).

40. Amlung M., Few L. R., Howland J., Rohsenow D. J., Metrik J., MacKillop J. Impulsivity and alcohol demand in relation to combined alcohol and caffeine use. Exp Clin Psychopharmacol 2013; 21: 467-74. Available at: https:// pubmed.ncbi.nlm.nih.gov/24364537 (accessed 20 October 2020).

41. Amlung M., McCarty K. N., Morris D. H., Tsai C. L., McCarthy D. M. Increased behavioral economic demand and craving for alcohol following a laboratory alcohol challenge. Addiction 2015; 110: 1421-8. Available at: http:// www.ncbi.nlm.nih.gov/pubmed/25732875 (accessed 20 October 2020).

42. Bertholet N., Murphy J. G., Daeppen J. B., Gmel G., Gaume J. The alcohol purchase task in young men from the general population. Drug Alcohol Depend 2015; 146: 39-44. Available at: https://pubmed.ncbi.nlm.nih.gov/25468819 (accessed 20 October 2020).

43. Cassidy R. N., Bernstein M. H., Magill M., MacKillop J., Murphy J. G., Colby S. M. Alcohol demand moderates brief motivational intervention outcomes in underage young adult drinkers. Addict Behav 2019; 98: 106044. Available at: https://pubmed.ncbi.nlm.nih.gov/31330464 (accessed 20 October 2020).

44. Dennhardt A. A., Yurasek A. M., Murphy J. G. Change in delay discounting and substance reward value following a brief alcohol and drug use intervention. J Exp Anal Behav 2015; 103: 125-40. Available at: https:// pubmed.ncbi.nlm.nih.gov/25533393 (accessed 20 October 2020).

45. Dennhardt A. A., Murphy J. G., McDevitt-Murphy M. E., Williams J. L. Drinking motives mediate the relationship between alcohol reward value and alcohol problems in military veterans. Psychol Addict Behav 2016; 30: 819-26. Available at: https://pubmed.ncbi.nlm.nih.gov/28068111 (accessed 20 October 2020).

46. Gray J. C., MacKillop J. Interrelationships among individual differences in alcohol demand, impulsivity, and alcohol misuse. Psychol Addict Behav 2014; 28: 282-7. Available at: https://pubmed.ncbi.nlm.nih.gov/23915370 (accessed 20 October 2020).

47. Herschl L. C., McChargue D. E., MacKillop J., Stoltenberg S. F., Highland K. B. Implicit and explicit alcohol-related motivations among college binge drinkers. Psychopharmacology 2012; 221: 685-92. Available at: https://pubmed.ncbi.nlm.nih.gov/22281603 (accessed 20 October 2020).

48. Hochster A., Block-Lerner J., Marks D. R., Erblich J. Mindfulness buffers the effects of cue-induced craving on alcohol demand in college drinkers. Addict Behav 2018; 84: 53-6. Available at: https://pubmed.ncbi.nlm.nih.gov/29626792 (accessed 20 October 2020). 
49. Joyner K. J., Meshesha L. Z., Dennhardt A. A., Borsari B., Martens M. P., Murphy J. G. High opportunity cost demand as an indicator of weekday drinking and distinctly severe alcohol problems: a behavioral economic analysis. Alcohol Clin Exp Res 2019; 43: 2607-19. Available at: https://www.ncbi. nlm.nih.gov/pubmed/31661166 (accessed 20 October 2020).

50. Kaplan B. A., Reed D. D., Murphy J. G., Henley A. J., Reed F. D. D., Roma P. G., et al. Time constraints in the alcohol purchase task. Exp Clin Psychopharmacol 2017; 25: 186-97. Available at: https://pubmed.ncbi.nlm.nih.gov/28240924 (accessed 20 October 2020).

51. Kaplan B. A., Reed D. D. Happy hour drink specials in the alcohol purchase task. Exp Clin Psychopharmacol 2018; 26: 156-67. Available at: https://www.ncbi.nlm.nih.gov/ pubmed/29355351 (accessed 20 October 2020).

52. Kiselica A. M., Borders A. The reinforcing efficacy of alcohol mediates associations between impulsivity and negative drinking outcomes. J Stud Alcohol Drugs 2013; 74: 490-9. Available at: https://pubmed.ncbi.nlm.nih.gov/23490580 (accessed 20 October 2020).

53. Lemley S. M., Kaplan B. A., Reed D. D., Darden A. C., Jarmolowicz D. P. Reinforcer pathologies: predicting alcohol related problems in college drinking men and women. Drug Alcohol Depend 2016; 167: 57-66. Available at: https:// www.ncbi.nlm.nih.gov/pubmed/27515726 (accessed 20 October 2020).

54. Lemley S. M., Fleming W. A. III, Jarmolowicz D. P. Behavioral economic predictors of alcohol and sexual risk behavior in college drinkers. Psychol Rec 2017; 67: 197-211. Available at: https://psycnet.apa.org/record/2017-20315-001 (accessed 20 October 2020).

55. Luciano M. T., Acuff S. F., McDevitt-Murphy M. E., Murphy J. G. Behavioral economics and coping-related drinking motives in trauma exposed drinkers: implications for the self-medication hypothesis. Exp Clin Psychopharmacol 2019; 28: 265. Available at: https://pubmed.ncbi.nlm.nih.gov/ 31380693 (accessed 20 October 2020).

56. Luehring-Jones P., Dennis-Tiwary T. A., Murphy J. G., Dennhardt A., Lindgren K. P., Yarmush D. E., et al. Favorable associations with alcohol and impaired self-regulation: a behavioral economic analysis. Drug Alcohol Depend 2016; 163: 172-8. Available at: https://pubmed.ncbi.nlm.nih.gov/ 27157107 (accessed 20 October 2020).

57. MacKillop J. Murphy JG. A behavioral economic measure of demand for alcohol predicts brief intervention outcomes. Drug Alcohol Depend 2007; 89: 227-33. Available at: https:// pubmed.ncbi.nlm.nih.gov/17289297 (accessed 20 October 2020).

58. MacKillop J., Miranda R. Jr., Monti P. M., Ray L. A., Murphy J. G., Rohsenow D. J., et al. Alcohol demand, delayed reward discounting, and craving in relation to drinking and alcohol use disorders. J Abnorm Psychol 2010; 119: 106-14. Available at: http://www.ncbi.nlm.nih.gov/pubmed/20141247 (accessed 20 October 2020).

59. Martinetti M. P., Caughron R. L., Berman H. L., Andre J., Sokolowski M. B. C., Wiley S., et al. The behavioral economics of alcohol demand in French and American University students. Alcohol Clin Exp Res 2019; 43: 531-44. Available at: https://pubmed.ncbi.nlm.nih.gov/30730582 (accessed 20 October 2020).

60. Merrill J. E., Aston E. R. Alcohol demand assessed daily: validity, variability, and the influence of drinking-related consequences. Drug Alcohol Depend 2020; 208: 107838.
Available at: https://www.ncbi.nlm.nih.gov/pubmed/ 31954948 (accessed 20 October 2020).

61. Meshesha L. Z., Soltis K. E., Wise E. A., Rohsenow D. J., Witkiewitz K., Murphy J. G. Pilot trial investigating a brief behavioral economic intervention as an adjunctive treatment for alcohol use disorder. J Subst Abuse Treat 2020; 113: 108002. Available at: https://www.sciencedirect.com/science/article/abs/pii/S0740547219303617 (accessed 20 October 2020).

62. Minhas M., Oshri A., Amlung M., Dennhardt A., Ferro M., Halladay J., et al. Latent profile analysis of heavy episodic drinking in emerging adults: a reinforcer pathology approach. Alcohol Clin Exp Res 2020, 44: 2130-40. Available at: https:// pubmed.ncbi.nlm.nih.gov/32965723/ (accessed 20 October 2020).

63. Morrell M. N., Reed D. D., Martinetti M. P. The behavioral economics of the bottomless cup: the effects of alcohol cup price on consumption in college students. Exp Clin Psychopharmacol 2020. Available at: https://www.ncbi.nlm.nih.gov/pubmed/ 32191070 (accessed 20 October 2020).

64. Morris V., Amlung M., Kaplan B. A., Reed D. D., Petker T., MacKillop J. Using crowdsourcing to examine behavioral economic measures of alcohol value and proportionate alcohol reinforcement. Exp Clin Psychopharmacol 2017; 25: 314-21. Available at: http://www.ncbi.nlm.nih.gov/ pubmed/28627926 (accessed 20 October 2020).

65. Morris V., Patel H., Vedelago L., Reed D. D., Metrik J., Aston E., et al. Elevated behavioral economic demand for alcohol in co-users of alcohol and cannabis. J Stud Alcohol Drugs 2018; 79: 929-34. Available at: https://pubmed.ncbi.nlm.nih.gov/ 30573024 (accessed 20 October 2020).

66. Murphy J. G., MacKillop J., Skidmore J. R., Pederson A. A. Reliability and validity of a demand curve measure of alcohol reinforcement. Exp Clin Psychopharmacol 2009; 17: 396-404. Available at: https://pubmed.ncbi.nlm.nih.gov/ 19968404 (accessed 20 October 2020).

67. Murphy J. G., Yurasek A. M., Dennhardt A. A., Skidmore J. R., McDevitt-Murphy M. E., MacKillop J., et al. Symptoms of depression and PTSD are associated with elevated alcohol demand. Drug Alcohol Depend 2013; 127: 129-36. Available at: https://pubmed.ncbi.nlm.nih.gov/22809894 (accessed 20 October 2020).

68. Naude G. P., Reed D. D., Thornton T., Amlung M. Dual use of alcohol and cannabis among college students: a reinforcer pathologies approach. Exp Clin Psychopharmacol 2020. Available at: https://www.ncbi.nlm.nih.gov/pubmed/ 32281812 (accessed 20 October 2020).

69. Noyes E. T., Schlauch R. C. Examination of approach and avoidance inclinations on the reinforcing value of alcohol. Addict Behav 2018; 79: 61-7. Available at: https:// pubmed.ncbi.nlm.nih.gov/29248864 (accessed 20 October 2020).

70. Patel H., Reed D. D., MacKillop J., Amlung M. Clarifying the relation between alcohol demand and alcohol-related relative reinforcement and driving after drinking in a Canadian community sample. Can J Addict 2019; 10: 16-23. Available at: https://journals.lww.com/cja/toc/2019/03000 (accessed 20 October 2020).

71. Ramirez J. J., Dennhardt A. A., Baldwin S. A., Murphy J. G., Lindgren K. P. Alcohol-approach inclinations and drinking identity as predictors of behavioral economic demand for alcohol. Exp Clin Psychopharmacol 2016; 24: 356-66. Available at: https://www.ncbi.nlm.nih.gov/pmc/articles/ PMC5048495 (accessed 20 October 2020). 
72. Ramirez J. J., Cadigan J. M., Lee C. M. Behavioral economic demand for alcohol among young adults who engage in simultaneous alcohol and marijuana use. Subst Abuse 2020; 41: 203-7. Available at: https://www.ncbi. nlm.nih.gov/pubmed/31638884 (accessed 20 October 2020).

73. Skidmore J. R., Murphy J. G., Martens M. P. Behavioral economic measures of alcohol reward value as problem severity indicators in college students. Exp Clin Psychopharmacol 2014; 22: 198-210. Available at: https://pubmed.ncbi.nlm.nih.gov/24749779 (accessed 20 October 2020).

74. Smith A. E., Martens M. P., Murphy J. G., Buscemi J., Yurasek A. M., Skidmore J. Reinforcing efficacy moderates the relationship between impulsivity-related traits and alcohol use. Exp Clin Psychopharmacol 2010; 18: 521-9. Available at: https:// pubmed.ncbi.nlm.nih.gov/21186926 (accessed 20 October 2020).

75. Strickland J. C., Stoops W. W. Stimulus selectivity of drug purchase tasks: a preliminary study evaluating alcohol and cigarette demand. Exp Clin Psychopharmacol 2017; 25: 198-207. Available at: https://pubmed.ncbi.nlm.nih.gov/ 28493743 (accessed 20 October 2020).

76. Teeters J. B., Pickover A. M., Dennhardt A. A., Martens M. P., Murphy J. G. Elevated alcohol demand is associated with driving after drinking among college student binge drinkers. Alcohol Clin Exp Res 2014; 38: 2066-72. Available at: https://pubmed.ncbi.nlm.nih.gov/24948397/ (accessed 20 October 2020).

77. Teeters J. B., Murphy J. G. The behavioral economics of driving after drinking among college drinkers. Alcohol Clin Exp Res 2015; 39: 896-904. Available at: https:// pubmed.ncbi.nlm.nih.gov/25871945 (accessed 20 October 2020).

78. Tripp J. C., Meshesha L. Z., Teeters J. B., Pickover A. M., McDevitt-Murphy M. E., Murphy J. G. Alcohol craving and demand mediate the relation between posttraumatic stress symptoms and alcohol-related consequences. Exp Clin Psychopharmacol 2015; 23: 324-31. Available at: https:// pubmed.ncbi.nlm.nih.gov/26375513 (accessed 20 October 2020).

79. Tucker J. A., Cheong J., Chandler S. D., Lambert B. H., Kwok H., Pietrzak B. Behavioral economic indicators of drinking problem severity and initial outcomes among problem drinkers attempting natural recovery: a cross-sectional naturalistic study. Addiction 2016; 111: 1956-65. Available at: https://pubmed.ncbi.nlm.nih.gov/27318078 (accessed 20 October 2020).

80. Wahlstrom L. C., McChargue D. E., Mackillop J. DRD2/ ANKK1 TaqI a genotype moderates the relationship between alexithymia and the relative value of alcohol among male college binge drinkers. Pharmacol Biochem Behav 2012; 102: 471-6. Available at: https://pubmed.ncbi.nlm.nih.gov/ 22728571 (accessed 20 October 2020).

81. Yurasek A. M., Murphy J. G., Dennhardt A. A., Skidmore J. R., Buscemi J., McCausland C., et al. Drinking motives mediate the relationship between reinforcing efficacy and alcohol consumption and problems. J Stud Alcohol Drugs 2011; 72: 991-9. Available at: https://pubmed.ncbi.nlm.nih.gov/ 22051213 (accessed 20 October 2020).

82. González-Roz A., Jackson J., Murphy C., Rohsenow D. J., MacKillop J. Behavioral economic tobacco demand in relation to cigarette consumption and nicotine dependence: a meta-analysis of cross-sectional relationships. Addiction
2019; 114: 1926-40. Available at: https://pubmed.ncbi. nlm.nih.gov/31313403 (accessed 20 October 2020).

83. Mackillop J., Murphy J. G., Tidey J. W., Kahler C. W., Ray L. A., Bickel W. K. Latent structure of facets of alcohol reinforcement from a behavioral economic demand curve. Psychopharmacology 2009; 203: 33-40. Available at: http:// www.ncbi.nlm.nih.gov/pubmed/18925387 (accessed 20 October 2020).

84. Bidwell L. C., Mackillop J., Murphy J. G., Tidey J. W., Colby S. M. Latent factor structure of a behavioral economic cigarette demand curve in adolescent smokers. Addict Behav 2012; 37: 1257-63. Available at: https:// pubmed.ncbi.nlm.nih.gov/22727784/ (accessed 20 October 2020).

85. Murphy J. G., Dennhardt A. A., Yurasek A. M., Skidmore J. R., Martens M. P., MacKillop J., et al. Behavioral economic predictors of brief alcohol intervention outcomes. J Consult Clin Psychol 2015; 83: 1033-43. Available at: https:// pubmed.ncbi.nlm.nih.gov/26167945 (accessed 20 October 2020).

86. Acuff S. F., Amlung M., Dennhardt A. A., MacKillop J., Murphy J. G. Experimental manipulations of behavioral economic demand for addictive commodities: a metaanalysis. Addiction 2020; 115: 817-31. Available at: https://pubmed.ncbi.nlm.nih.gov/31656048 (accessed 20 October 2020).

87. Presley C. A., Pimentel E. R. The introduction of the heavy and frequent drinker: a proposed classification to increase accuracy of alcohol assessments in postsecondary educational settings. J Stud Alcohol 2006; 67: 324-31. Available at: https://pubmed.ncbi.nlm.nih.gov/16562416 (accessed 20 October 2020).

88. Chandley R. B., Luebbe A. M., Messman-Moore T. L., Rose M. W. Anxiety sensitivity, coping motives, emotion dysregulation, and alcohol-related outcomes in college women: a moderated-mediation model. I Stud Alcohol Drugs 2014; 75: 83-92. Available at: https:// pubmed.ncbi.nlm.nih.gov/24411800 (accessed 20 October 2020).

89. Skidmore J. R., Murphy J. G. The effect of drink Price and next-day responsibilities on college student drinking: a behavioral economic analysis. Psychol Addict Behav 2011; 25: 57-68. Available at: https://www.ncbi. nlm.nih.gov/pubmed/21142332 (accessed 20 October 2020).

90. Studer J., Baggio S., Dupuis M., Mohler-Kuo M., Daeppen J.-B., Gmell G. Drinking motives as mediators of the associations between reinforcement sensitivity and alcohol misuse and problems. Front Psychol 2016; 7: 718. Available at: https://www.ncbi.nlm.nih. gov/pmc/articles/PMC4878201/ (accessed 20 October 2020).

91. Cozzoli D. K., Tanchuck-Nipper M. A., Kaufman M. N., Horowitz C. B., Finn D. A. Environmental stressors influence limited-access ethanol consumption by $\mathrm{C} 57 \mathrm{BL} / 6 \mathrm{~J}$ mice in a sex-dependent manner. Alcohol 2014; 48: 741-54. Available at: https://pubmed.ncbi.nlm.nih.gov/25459519 (accessed 20 October 2020).

92. Foster D. W., Young C. M., Steers M.-L., Quist M. C., Bryan J. L., Neighbors C. Tears in your beer: gender differences in coping drinking motives, depressive symptoms and drinking. Int $J$ Ment Health Addict 2014; 12: 730-46. Available at: https:// www.ncbi.nlm.nih.gov/pmc/articles/PMC4267111 (accessed 20 October 2020). 
93. Feng C., Wang H., Lu N., Chen T., He H., Lu Y., et al. Log-transformation and its implications for data analysis. Shanghai Arch Psychiatry 2014; 26: 105-9. Available at: https://www.ncbi. nlm.nih.gov/pmc/articles/PMC4120293/ (accessed 20 October 2020).

94. Osborne J. W. Notes on the use of data transformations. Pract Assess Res Eval 2003; 8: 1-7. Available at: https:// scholarworks.umass.edu/pare/vol8/iss1/6 (accessed 20 October 2020).

95. Peacock J. L., Kerry S. M., Balise R. R. Presenting Medical Statistics from Proposal to Publication. Oxford: Oxford University Press; 2017.

\section{Supporting Information}

Additional supporting information may be found online in the Supporting Information section at the end of the article.

Data S1: Supplementary figs. 1-20.

Table S1: PRISMA-IPD Checklist of items to include when reporting a systematic review and meta-analysis of individual participant data (IPD). 